\title{
Relationship of Transformation Efficiency and Metabolites Induced in Korean Soybean Cotyledons Treated with Sonication
}

\author{
Kitae Song*, Won Cheol Yim**, Gun-Ho Jung***, Sun Lim Kim***, Young-Up Kwon***, Byung-Moo Lee* ${ }^{\dagger}$ \\ *Department of Life Science, Dongguk Univ-Seoul, 100-715, Korea \\ **Department of Plant Biotechnology, Dongguk Univ-Seoul, 100-715, Korea \\ ***National Institute of Crop Science, RDA, Suwon 441-857, Korea
}

\begin{abstract}
The interaction between Agrobacterium and soybean has been studied at the transcriptome level but not at the metabolic level. However, it is necessary to investigate the difference in metabolites between susceptible and non-susceptible cultivars for high efficiency transformation. We investigated the difference in metabolites from sonicated soybean cotyledons of Korean cultivars and Bert cultivar. To identify difference in metabolites, sonicated extracts were analysed by Fourier transform ion cyclotron resonance mass spectrometry (FT-ICR/MS). The soybean cultivars were classified by susceptibility using green fluorescent protein expression. We found a difference in metabolites between the high susceptible and low susceptible cultivars. The FT-ICR/MS experimental $\mathrm{m} / \mathrm{z}$ data of different metabolites were compared with theoretical $\mathrm{m} / \mathrm{z}$ in KNApSAcK database. The candidate list was made using KNApSAcK and focused on phenolic compounds. These candidate metabolites are speculated to influence factors in the interaction. This list of candidates may be useful to investigate the interaction between Agrobacterium and plants to increase transformation efficiency.
\end{abstract}

Keywords : soybean, metabolites, interaction, Agrobacterium, FT-ICR/MS

Soybean (Glycine $\max$ L.) is an important crop because of its high oil and protein contents in seeds. Soybean is the predominant protein source in animal feed and cooking oil (Schmutz et al. 2010). Soybean is responsible for more than $\$ 5$ billion in annual export value to the U.S. economy (Gunstone, 2001).

Considerable success has been obtained in Agrobacteriummediated transformation of soybean (Trick \& Finer, 1998; Santarém et al. 1998; Olhoft \& Somers, 2001; Olhoft et al. 2003), after the first transgenic soybean plant was obtained
(Hinchee et al. 1988). In an effort to solve problems with host-specific Agrobacterium strains and low transformation efficiency researchers have included thiol compounds in the co-cultivation medium (Trick and Finer 1998; Olhoft and Somers 2001; Negishi 2007). Various transformation methods has been developed using powerful tools such as green fluorescent protein (GFP) and sonication. The use of GFP has provided a tool for fast and simple monitoring. Because visualisation of GFP does not kill cells, fluorescence can be used to study gene expression in vivo (Chalfie et al. 1994) or to monitor viral or bacterial infection events over time (Baulcombe et al. 1995; Gage et al. 1996; Oparka et al. 1997). Sonication-assisted Agrobacteriummediated transformation (SAAT) is an efficient Agrobacteriumbased transformation technology (Trick and Finer, 1997). This method consists of subjecting the target plant tissue to brief periods of ultrasound while it is immersed in an Agrobacterium suspension. The wounding due to sonication creates entry points for the bacteria and may stimulate the production of signalling molecules involved in the T-DNA transfer process (Meurer at el., 1998; Gelvin 2000). However, successful transformation has been accomplished in only a few mature soybean cultivars (Yan et al. 2000; Donaldson \& Simmonds, 2000; Olhoft et al. 2003).

Improvements in Agrobacterium transformation depend on several factors including plant genotype, explant vigour, Agrobacterium strain, and co-cultivation. Some studies have shown an interaction between strains of Agrobacterium tumefaciens and soybean cultivars (Delzer et al. 1990; Ditt et al. 2001; Veena et al. 2003). Acetosyringone is a plant phenolic compound naturally secreted by wounded plant

\footnotetext{
Corresponding author: (Phone) +82-2-2260-3307 (E-mail) bmlee@dongguk.edu

$<$ Received 28 December, 2012; Revised 18 March, 2013; Accepted 22 March, 2013>
} 
cells that acts as an inducer of Agrobacterium virulence genes (Stachel et al. 1985; Tang 2003). Phenolic compounds have benzene rings with some hydroxyl groups and are produced by plants mainly to protect against stress. In the majority of cases, the phenolic compounds kill many microorganisms, and some pathogens can use these metabolites to their own advantage. Agrobacterium has evolved mechanisms to counteract and utilise plant defences for their own advantage (Matilla et al. 2007; Hartmann et al. 2008). These metabolites are related to the interaction between Agrobacterium and host plant cells (Long 1996; Parker et al. 1997).

Fourier transform ion cyclotron resonance mass spectrometry (FT-ICR/MS) is a analytic method with extremely high resolution and sensitivity (Marshall 1985). FT-ICR/MS allows direct analyses of samples without chromatographic steps and structural reactions, and high-throughput metabolic profiling studies can be conducted by assigning only one or a few molecular formulas to each single $\mathrm{m} / \mathrm{z}$ value in the spectra. Several applications using FT-ICR/MS for plant metabolomics have been published (Aharoni et al. 2002; Hirai et al. 2004; Nakamura et al. 2007; Ohta et al. 2007). Algorithms have been developed to generate reliable liquid chromatography-mass spectrometry and FT-ICR/MS data to identify and measure the abundance of molecules. In the peak-picking algorithm, the highest intensity data points are used without an $\mathrm{m} / \mathrm{z}$ centroid (Clauser et al. 1999). The frequency and mass difference between the data points is given to describe the error due to this simple peak detection (Titulaer et al. 2006) and the average noise signal intensity, the baseline correction, is calculated according to a method developed by Horn et al. Many programs has been developed and used such as "mMass", which is a cross-platform environment to precisely analyse individual mass spectra (Strohalm et al. 2010).

These programs make analysis of FT-ICR/MS data and metabolic profiling easy. In particular, development of data processing (Dr. DMASS) and a metabolite-species relationship database (KNApSAcK) enables the identification of candidate metabolites (Oikawa et al. 2006). This system was developed to obtain information on metabolites, secondary metabolites, and their corresponding species. The database has a tool that can be used for analysing FT-ICR/MS data.
The database enables searches using FT-ICR/MS data to identify metabolite-species relationships with detailed metabolite information.

The objective of this study was to examine the interaction between Agrobacterium and soybean cotyledons. GFP expression on cotyledons and the genotype-specific metabolites induced from sonicated cotyledons were evaluated using Korean soybean cultivars and the U.S. cultivar 'Bert'. This is the first report to study the interaction between Agrobacterium and soybean at the metabolic level.

\section{MATERIALS \& METHODS}

\section{Preparation of explants}

The three Korean soybean cultivars, 'Taekwang', 'Iksannamul', 'Pungsannamul', and the US cultivar 'Bert' were used. Seeds were obtained from the Rural Development Administration, Republic of Korea in 2010. Soybean seeds were washed with $70 \%$ ethanol with shaking for $1 \mathrm{~min}$. The seeds were kept in a desiccator for $16 \mathrm{hr}$ under chlorine gas for sterilisation, which was produced with 100 $\mathrm{ml}$ of bleach and $5 \mathrm{ml}$ of $12 \mathrm{~N} \mathrm{HCl}$. After sterilisation, the seeds were transferred to germination media containing B5 salts and vitamins (Gamborg et al. 1968), $30 \mathrm{mg} / \mathrm{l}$ sucrose, $\mathrm{pH}$ 5.7. All plants were grown under a $16 \mathrm{hr}$ photoperiod at $25^{\circ} \mathrm{C}$ After $4-5$ days, the seed coat and hypocotyl were removed, and the cotyledon was separated. The cotyledonary node, containing the cotyledon, was used for transformation experiments.

\section{Binary vectors and Agrobacterium strains}

The Agrobacterium tumefaciens strains used for transformation was EHA105. The strains contained the pCAMBIA 1303 binary vector (CAMBIA, Canberra, Australia) including the mGFP gene. A single colony was isolated and cultured in $5 \mathrm{ml}$ liquid YEB media containing $50 \mathrm{mg} / \mathrm{l}$ rifampicin and $50 \mathrm{mg} / \mathrm{l}$ kanamycin overnight with $200 \mathrm{rpm}$ shaking at $25^{\circ} \mathrm{C}$ A $25 \mu \mathrm{l}$ aliquot of culture media was transferred to $500 \mathrm{ml}$ of YEP medium with antibiotics overnight at $25^{\circ} \mathrm{C}$ with shaking until optical density (OD) reached a value of 0.4-0.5 in $600 \mathrm{~nm}$. The resulting culture media was centrifuged at $4000 \mathrm{rpm}$ for $10 \mathrm{~min}$ to collect the bacterial pellet. The pellets were resuspended and 
adjusted to an $\mathrm{OD}_{600}$ of $0.8-1.0$ with co-cultivation medium. The co-cultivation medium was composed of B5 salts and vitamins, $44 \mu \mathrm{M}$ BAP, $1 \mu \mathrm{M}$ IBA, $100 \mu \mathrm{M}$ acetosyringone, and $30 \mathrm{mg} / \mathrm{l}$ sucrose, $\mathrm{pH}$ 5.5. The bacterial suspension was prepared immediately prior to use.

\section{Inoculation and co-cultivation of Agrobacterium}

The transformation protocol was based on the SAAT protocol of Townsend and Thomas (1993). The sonication is useful to wounding equally, the wounding induced metabolites related to interaction. The transformation experimental units were composed of 10 explants placed in $30 \mathrm{ml}$ of Agrobacterium suspension and sonicated for 600 seconds. After the sonication, cotyledons were cultured for an additional $30 \mathrm{~min}$ at $150 \mathrm{rpm}$ with shaking. A $200 \mu \mathrm{l}$ aliquot of Agrobacterium suspension was transferred to 30 $\mathrm{ml}$ liquid YEB media to measure the relationship between sonicated cotyledons and Agrobacterium growth,. The O.D. value of Agrobacterium suspension was measured at 600 $\mathrm{nm}$ after 14 and $16 \mathrm{hr}$. An Agrobacterium suspension without soybean cotyledons was measured as a control. After sonication, each tube of explants was rinsed with double distilled water and placed in solid co-cultivation media (as above with agarose added) and incubated at 2 $5^{\circ} \mathrm{C}$ in the dark for $72 \mathrm{hr}$. After co-cultivation, cotyledons were rinsed with liquid post co-cultivation medium containing B5 salts and vitamins, $5 \mu \mathrm{M}$ BAP, $1 \mu \mathrm{M}$ IBA, and $30 \mathrm{~g} / \mathrm{l}$ sucrose (pH 5.7), $250 \mathrm{mg}$ cefoxtaxium, and 100 $\mathrm{mg}$ ticarcillin. The cotyledons were subsequently cultured on solid post co-cultivation medium.

\section{Visualization of GFP expression}

The soybean cotyledons on a plate were assayed for GFP gene expression. All cotyledons were assayed at 10 days after co-cultivation. GFP expression was observed by a LED $450 \mathrm{~nm}$ blue light source with a Kodak Wratten filter \#15. The GFP foci per cotyledon (Foci/Cot) and percentage of response (Resp/Cot) were measured on the abaxial surface of the cotyledon (Meurer et al. 1998). The Foci/Cot was the number of GFP expressing foci on each cotyledon that responded with more than one spot of GFP expression, and the percentage of the response was the number of cotyledons with more than one spot of GFP expression among total explants.

\section{Analysis of $\mathrm{FT}-\mathrm{ICR} / \mathrm{MS}$}

FT-ICR/MS was used to compare the substances secreted from soybean cotyledons. Cotyledons were sonicated in water without Agrobacterium for an accurate analysis. Metabolites were analysed using an FT-ICR/MS instrument (Korea Basic Science Institute, Osong, Chungbuk, Korea) with a 15T-FT-ICR, set on electrospray ionisation positive mode. The samples were injected directly by syringe pump at a flow rate of $2 \mu \mathrm{min}^{-1}$. The samples were diluted 1:10 with $100 \%$ acetonitrile. Twenty spectral scans were performed for each sample. Experimental values for the $\mathrm{m} / \mathrm{z}$ data were corrected to their theoretical values to calibrate all spectral data. A metabolite-species relationship database (KNApSAcK) was used to predict the candidate metabolites (Oikawa A et al. 2006; Shinbo Y et al. 2006).

\section{Normalization}

The FT-ICR/MS data were controlled by the mMASS, version 5.0 program. For normalisation, peaks were separated from noise if they had a signal to noise intensity $(\mathrm{S} / \mathrm{N})>3$. The spectra were smoothed using the moving average method and deisotoped. Precursor error tolerance was set to $100 \mathrm{ppm}$, and mass fragment error tolerance was set to 0.5 DA. Normalised peaks were compared with the tolerance set to $0.005 \mathrm{Da}$.

Data were analysed by analysis of variance, and the means were compared using Duncan's multiple range test. A $p<0.05$ was considered significant.

\section{RESULTS \& DISCUSSION}

\section{GFP expression on cotyledons}

To identify relation between transformation efficiency and metabolites, we used the GFP expression. GFP expression on cotyledons was evaluated at 10 days after co-cultivation with Agrobacterium (Table 1, Fig. 1). The spots of GFP expression from EHA105 were counted on the abaxial side of the cotyledon. The Foci/CotN and Resp/CotN were used to evaluate GFP expression. The percentage response was 26.3, 20.0, 16.3, and 18.0\% in 'Bert', 'Taekwang', 'Iksannamul' and 'Pungsannamul', respectively. The 'Bert' Foci/CotN 
Table 1. GFP expression on cotyledons of Bert, Taekwnag, Iksannamul, Pungsannamul at 10 days after co-cultivation with EHA105.

\begin{tabular}{lcc}
\hline \hline Variety & Foci/CotN & Response $/ \operatorname{CotN}^{2}$ \\
\hline Bert & $9.8 \pm 1.7^{\mathrm{a} 3}$ & 26.3 \\
\hline Taekwang & $7.8 \pm 1.4^{\mathrm{ab}}$ & 20.0 \\
\hline \hline Iksannamul & $3.0 \pm 0.4^{\mathrm{c}}$ & 16.3 \\
\hline Pungsannamul & $4.8 \pm 0.7^{\mathrm{bc}}$ & 18.0 \\
\hline
\end{tabular}

${ }^{1}$ Foci/CotN is the number of GFP spots on each cotyledon responsed with more than one GFP spot.

${ }^{2}$ Response/CotN is the number of cotyledon with more than one GFP spot among total explants.

${ }^{3}$ Different letters within column indicate significant differences at $\mathrm{p}<0.05$ (DMRT).

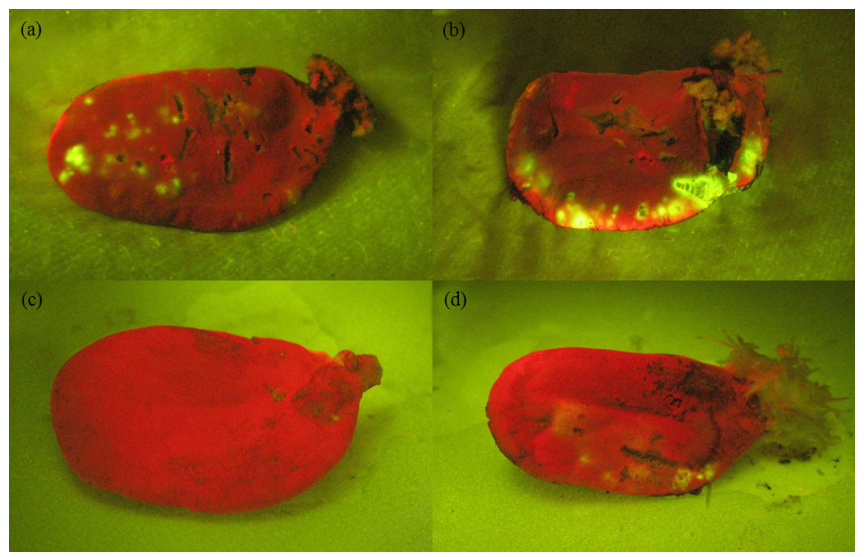

Fig. 1. Photographs showing GFP expression in cotyledon of soybean cultivars. (a) Bert, (b) Taekwang, (c) Iksannamul, (d) Pungsannamul.

was significantly different, and 'Taekwang' showed the highest Foci/CotN. As a whole, 'Bert' and 'Taekwang' were showed higher score in Foci/CotN and Resp/ContN than 'Iksannamul' and 'Pungsannamul'. These results strongly suggest a relationship between the variants and Agrobacterium.

These results are suggesting that genotype-specific metabolites affect susceptibility to Agrobacterium. Many studies have reported that some metabolites, such as phenolic compounds, affect the interaction between Agrobacterium and plant cells (Owens and Smigocki, 1988; Tzfira and Citovsk, 2002; Zaltsman et al., 2010). The 'Bert' and 'Taekwang' cultivars were more susceptible than 'Iksannamul' and 'Pungsannamul' from the GFP expression results.

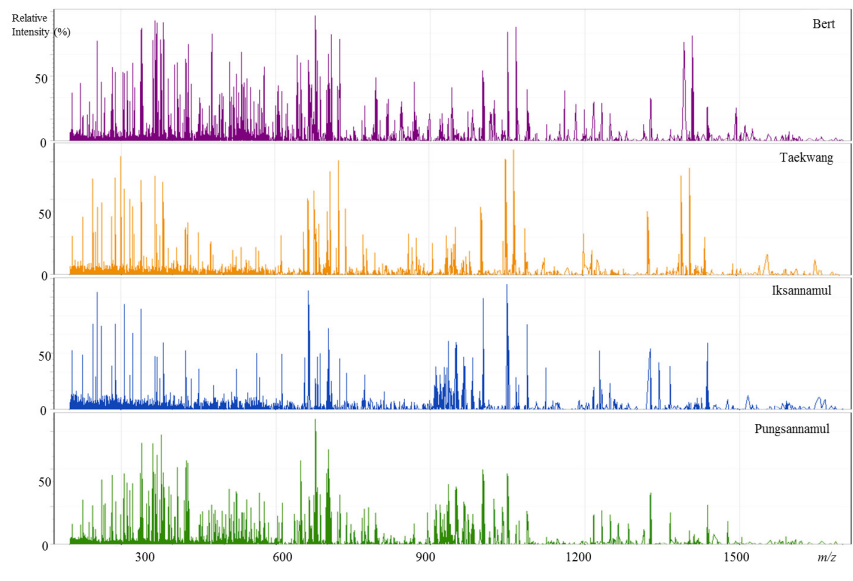

Fig. 2. Positive mode ESI FT-ICR mass spectrum of whole library.

\section{Difference in metabolites}

Several studies have shown that metabolites such as phenolic compounds affect bacterial growth and interaction (Cushnie \& Lamb, 2005; Ferrazzano et al., 2009; Taguri et al., 2006). As known, 'Bert' was used for soybean transformation as a good explant (Olhoft et al., 2003; Zeng et al., 2004). But Korean soybean cultivars have low transformation efficiency compared with other cultivars, also successful transformation in Korean soybean had not yet reported. To identify the reason of low transformation efficiency, the metabolites from sonicated cotyledons were analysis using FT-ICR/MS (Fig. 2). The results showed that some peak of Bert is different from peak of Korean cultivars. However, Taekwang have some similar peaks of Bert's peak. It is expected that Taekwang's susceptibility is similar to Bert.

\section{Candidate metabolites}

The FT-ICR/MS spectra were analysed using mMASS software. After normalisation, the observed peaks were compared with a tolerance of $0.005 \mathrm{Da}$. We focused on the overlapping peaks between 'Bert' and 'Taekwang', which are highly susceptible cultivars, and between 'Iksannamul' and 'Pungsannamul', which are low susceptibility cultivars. We suggest that the metabolites of the highly susceptible cultivars are related to the interaction between Agrobacterium and soybean cells. The peaks at masses of 707.222, 723.196, 1065.312, and $1407.428 \mathrm{~m} / \mathrm{z}$ had intensities above the $\mathrm{S} / \mathrm{N}$ threshold in the 'Bert' and 'Taekwang' cultivars. 


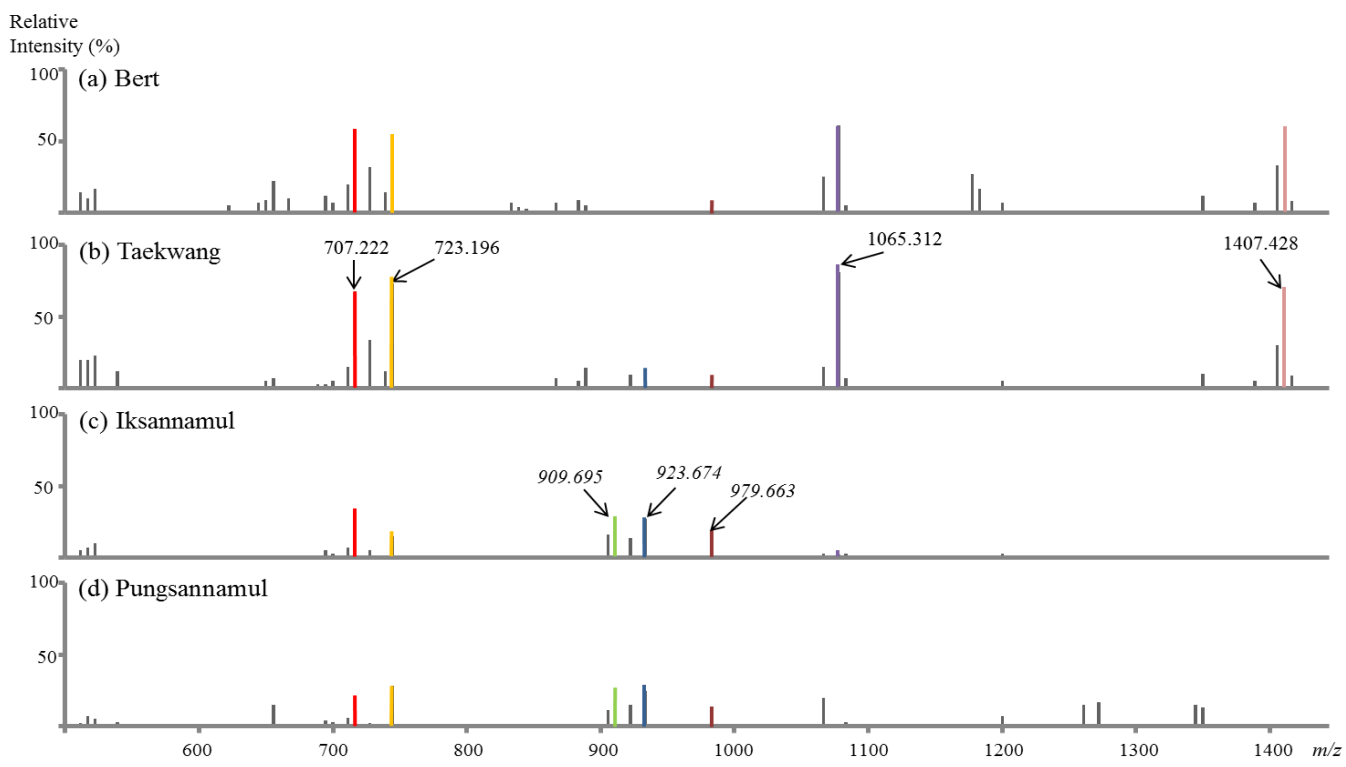

Fig. 3. The specific peaks of each cultivar selected by FT-ICR mass spectrum.

Table 2. The candidates at each peaks. The list were selected by comparing between theorical $\mathrm{m} / \mathrm{z}$ and experimental $\mathrm{m} / \mathrm{z}$ using KNApSAcK database.

\begin{tabular}{|c|c|c|c|c|c|c|c|}
\hline $\begin{array}{c}\text { Experimental } \\
\mathrm{m} / \mathrm{z}^{1}\end{array}$ & Adducts $^{2}$ & $\begin{array}{c}\text { Theorical } \\
\mathrm{m} / \mathrm{z}^{3}\end{array}$ & Difference $^{4}$ & $\begin{array}{c}\text { Molecular } \\
\text { Formula }\end{array}$ & Metabolites & Organism & Bert \\
\hline \multirow{11}{*}{707.222} & \multirow{7}{*}{$\mathrm{H}^{-}$} & 708.190 & 0.039 & $\mathrm{C}_{32} \mathrm{H}_{36} \mathrm{O}_{18}$ & Kaempferide 3-Rhamnoside-7-(6"-Succinylglucose) & Allium & \multirow{11}{*}{58.343} \\
\hline & & 708.204 & 0.026 & $\mathrm{C}_{33} \mathrm{H}_{36} \mathrm{~N}_{6} \mathrm{O}_{8} \mathrm{~S}_{2}$ & Leptosin M1 & Leptoshaeria & \\
\hline & & 708.227 & 0.009 & $\mathrm{C}_{33} \mathrm{H}_{40} \mathrm{O}_{17}$ & Glomeratose C & Polygala & \\
\hline & & 708.263 & 0.034 & $\mathrm{C}_{34} \mathrm{H}_{44} \mathrm{O}_{16}$ & 4'-Cinnamoylmussatioside & Mussatia & \\
\hline & & 708.205 & 0.024 & $\mathrm{C}_{36} \mathrm{H}_{36} \mathrm{O}_{15}$ & Dicerandrol B & Phomopsis & \\
\hline & & 708.252 & 0.023 & $\mathrm{C}_{36} \mathrm{H}_{45} \mathrm{BRN}_{4} \mathrm{O}_{6}$ & Jaspamide & Jaspis & \\
\hline & & 708.242 & 0.013 & $\mathrm{C}_{37} \mathrm{H}_{40} \mathrm{O}_{14}$ & Firmianone $\mathrm{C}$ & Firmiana & \\
\hline & \multirow{2}{*}{$\mathrm{H}^{+}$} & 706.211 & 0.004 & $\mathrm{C}_{33} \mathrm{H}_{38} \mathrm{O}_{17}$ & Sinocrassoside A5 & Sinocrassula & \\
\hline & & 706.120 & 0.018 & $\mathrm{C}_{40} \mathrm{H}_{34} \mathrm{~N}_{4} \mathrm{O}_{16}$ & Antibiotic $\mathrm{Pa} 42702 \mathrm{~B}$ & Flexibacter & \\
\hline & \multirow{2}{*}{$\mathrm{Na}^{+}$} & 684.263 & 0.03 & $\mathrm{C}_{32} \mathrm{H}_{44} \mathrm{O}_{16}$ & Yadanzioside E & Brucea & \\
\hline & & 684.205 & 0.027 & $\mathrm{C}_{34} \mathrm{H}_{36} \mathrm{O}_{15}$ & Agnucastoside $\mathrm{C}$ & Vitex Agnus- & \\
\hline \multirow{11}{*}{723.196} & \multirow{7}{*}{$\mathrm{H}^{-}$} & \multirow{3}{*}{724.221} & \multirow{2}{*}{0.018} & \multirow{2}{*}{$\mathrm{C}_{33} \mathrm{H}_{40} \mathrm{O}_{18}$} & Kaempferol 3-Rhamnosyl-(1->4)-Rhamnoside-7- & Cassinopsis & \multirow{11}{*}{54.638} \\
\hline & & & & & 5,7,4"-Trihydroxyis O-Flavone 7-O-Alpha-L- & Sophora & \\
\hline & & & 0.008 & $\mathrm{C}_{35} \mathrm{H}_{36} \mathrm{~N}_{2} \mathrm{O}_{15}$ & Pradimicin $\mathrm{Fb}$ & Actinomadur & \\
\hline & & & & & Kaempferol 3-(2"-P-Coumaryl-Rhamnoside)-7- & Cheilanthes & \\
\hline & & 724.200 & 0.003 & $\mathrm{C}_{36} \mathrm{H}_{36} \mathrm{O}_{16}$ & 3-O-Alpha-L-Rhamnopyranosylcatechin-(4Alpha- & Quercus & \\
\hline & & 124.200 & 0.003 & $\mathrm{C}_{36} \mathrm{H}_{36} \mathrm{U}_{16}$ & Catechin-(4Alpha->8)-Catechin-3-O- & Quercus & \\
\hline & & & & & Kaempferol 3-(3"-P-Coumaryl-Rhamnoside)-7- & Cheilanthes & \\
\hline & \multirow{3}{*}{$\mathrm{H}^{+}$} & 722.206 & 0.017 & $\mathrm{C}_{33} \mathrm{H}_{38} \mathrm{O}_{18}$ & 6"'-(3-Hydroxy-3-Methylglutaroyl)Isoviolanthin & Glycyrrhiza & \\
\hline & & 722.185 & 0.004 & $\mathrm{C}_{36} \mathrm{H}_{34} \mathrm{O}_{16}$ & 5-O-Beta-D-Glucosylluteoliflavan-(40>8)- & Sorghum & \\
\hline & & 722.200 & 0.011 & $\mathrm{C}_{40} \mathrm{H}_{34} \mathrm{O}_{13}$ & Formononetic 7-O-(2",6"-Di-O-(E-P- & Pterocarpus & \\
\hline & $\mathrm{Na}^{+}$ & 700.221 & 0.015 & $\mathrm{C}_{31} \mathrm{H}_{40} \mathrm{O}_{18}$ & Welloside & Veronica & \\
\hline 923.674 & $\mathrm{Na}^{+}$ & 900.690 & 0.005 & $\mathrm{C}_{51} \mathrm{H}_{96} \mathrm{O}_{12}$ & Sch60065 & Acremonium & 0 \\
\hline \multirow{6}{*}{1065.312} & \multirow{3}{*}{$\mathrm{N} / \mathrm{A}^{5}$} & \multirow{3}{*}{1065.288} & \multirow{3}{*}{0.024} & \multirow{3}{*}{$\mathrm{C}_{51} \mathrm{H}_{53} \mathrm{O}_{25}$} & Cyanidin 3-[2-(6-P-Coumaryglucosyl)-6-P- & Ipomoea & \multirow{6}{*}{61.006} \\
\hline & & & & & Pelargonidin 3-O-[2-O-(6-€-Caffeoyl-Beta-D- & Raphanus & \\
\hline & & & & & Pelargonidin 3-(2-(6-Caffeylglucosyl)-6-P- & Raphanus & \\
\hline & \multirow{3}{*}{$\mathrm{H}^{+}$} & \multirow{3}{*}{1064.301} & \multirow{3}{*}{0.004} & \multirow{3}{*}{$\mathrm{C}_{48} \mathrm{H}_{56} \mathrm{O}_{27}$} & Kaempferol3-Neohesperidoside-7-2"-[- & Allium & \\
\hline & & & & & Capilliposide I & Lysimachia & \\
\hline & & & & & Chakaflavonoside A & Camellia & \\
\hline \multirow{2}{*}{1407.428} & \multirow{2}{*}{$\mathrm{NH}^{+}$} & \multirow{2}{*}{1389.372} & \multirow{2}{*}{0.022} & \multirow{2}{*}{$\mathrm{C}_{66} \mathrm{H}_{69} \mathrm{O}_{33}$} & Delphinidin 3-Glucoside-7,3',5'-Tri(6-O-P- & Dianella & \multirow{2}{*}{57.404} \\
\hline & & & & & Cyanidin 3-O-[2-O-(6-O-E-Coumaroyl-Beta-D- & Ipomoea & \\
\hline
\end{tabular}


Peaks at masses of 907.679, 909.695, 923.674, 931.679, and $979.663 \mathrm{~m} / \mathrm{z}$ were shown in 'Iksannamul' and 'Pungsannamul' (Fig. 3). Some peaks overlapped in all cultivars, nevertheless, there were some differences in intensity.

The masses of the peaks were searched using KNApSAcK, which is a mass spectra dataset. The KNApSAcK data were analysed focusing on ion adducts $[\mathrm{M}+\mathrm{K}]^{+},[\mathrm{M}+\mathrm{Na}]^{+}$, $[\mathrm{M}+\mathrm{NH} 4]^{+},[\mathrm{M}+\mathrm{H}]^{+}$, and $[\mathrm{M}-\mathrm{H}]^{-}$(Tautenhahn et al., 2007; Iijima et al., 2008). The experimental FT-ICR/MS $m / z$ data were compared with the theoretical $m / z$ in the KNApSAcK database. The candidates were sorted by errors $<0.05 \mathrm{~m} / \mathrm{z}$ between the experimental $\mathrm{m} / \mathrm{z}$ and the theoretical $m / z$. The common metabolites of the highly susceptible cultivars had a few errors from the theoretical $m / z$. The $m / z$ of $723.196,1065.312$, and 1407.428 showed that some phenolic compounds may have influenced the interaction between Agrobacterium and soybeans (Table 2).

Organisms in the KNApSAcK database are used help to speculate on the origin of metabolites such as the species, genus, family, or kingdom. Therefore, we focused on the phenolic metabolites in the plant kingdom. Phenolic compounds play a role activating bacterial nodulation (nod) and virulence (vir) gene networks as well as quorum signalling (Brencic et al., 2004; Bhattacharya et al. 2010). Eleven candidates were searched at $707.222 \mathrm{~m} / \mathrm{z}$. The candidates included phenolic compounds such as kaempferol and cinnamaldehydes. The families of kaempferol and hydroxycinnamides are associated with vir gene induction (Zerback et al., 1989; Berthelot et al., 1998; Joubert et al., 2004). Some candidate metabolites had no relationship with the interaction between Agrobacterium and soybeans. Dicerandrol B from fungi, jaspamide from the animal kingdom and the antibiotic pa 42702B from bacteria were not associated with the soybean metabolites. Many candidates, which were related to phenolic compounds, were shown at $723.196 \mathrm{~m} / \mathrm{z}$. All metabolites at 723.196 $\mathrm{m} / \mathrm{z}$ were from plants, including many phenolic compounds such as kaempferol, flavonone, catechins, and coumaroyl hydrates. Kaempferol and flavonone are metabolites that induce the vir gene in Agrobacterium (Latha and Mahadevan, 1997; Jiang, 2003). Catechins and coumarins are metabolites used as recognition receptors in Agrobacterium (Spencer and Towers, 1988; John et al., 2009). After normalisation, two peaks were shown at $1065.288 \mathrm{~m} / \mathrm{z}$ and $1064.301 \mathrm{~m} / \mathrm{z}$ at $1065.312 \mathrm{~m} / z$. The $1065.288 \mathrm{~m} / \mathrm{z}$ peak was potentially cyanidin or pelargonidin, which are anthocyanidins. Anthocyanidins are flavononols, which determine floral colour, but they are not associated with the interaction between Agrobacterium and soybean. However, 1064.301 $\mathrm{m} / \mathrm{z}$ with $\mathrm{H}^{+}$adducts included metabolites related to the interaction (Koes et al., 1994; Holton and Cornish, 1995). Kaempferol is induced by the vir gene of Agrobacterium, and flavonoids and flavonols induce the nod gene in Rhizobium (Cohen et al., 2001; Stougaard, 2000). The $1407.428 \mathrm{~m} / \mathrm{z}$ peak contained two candidates coumaroyl and cyanidin. Coumaroyl and cynidin are anthocyanins related to flower colour (Holton and Cornish, 1995). Some common metabolites in the highly susceptible cultivars were candidates associated with the interaction between Agrobacterium and soybean. Especially, 707.222, 723.196, and $1065.312 \mathrm{~m} / \mathrm{z}$ were involved in phenolic compounds such as keamperol, catechin, cinnamaldehydes that play an important role in the interaction between Agrobacterium and soybean cells (Nester. 1995; Bhattacharya et al. 2010). In contrast, the common metabolites of the low susceptibility cultivars had large errors $>0.05$ except $923.674 \mathrm{~m} / z$. SCH 60065 was the only candidate at $923.674 \mathrm{~m} / z$. SCH 60065 is an antibiotic metabolite that has a role as a receptor inhibitor in microbes (Hegde et al. 1997). No other peaks were detected in the low susceptibility cultivars with < 0.05 error. This may have been due to a lack of studies on secondary metabolites; thus, these peaks are unresolved. Differences in metabolites were observed between the high and low susceptible cultivars and some candidate metabolites had an effect on the interaction between Agrobacterium and soybean cells.

We found the difference of metabolites between each cultivar. The metabolites were identified by sonication and FT-ICR/MS may have caused the difference in susceptibility to Agrobacterium. 'Bert' and 'Taekwang' were classified as highly susceptible cultivars based on GFP expression. To clarify reason of different transformation efficiency, the experimental FT-ICR/MS $m / z$ data were compared with the theoretical $m / z$ in the KNApSAcK database and we found some candidate metabolites. The candidates included some phenolic compounds that influence the interaction between 
Agrobacterium and soybean cells. The candidate metabolites of the highly susceptible cultivars may influence interaction and transformation efficiency. The metabolite data of the high and low susceptibility cultivars may be useful to investigate the interaction between Agrobacterium and plants and increase transformation efficiency.

\section{ACKNOWLEDGEMENTS}

This work was conducted with the support of the Cooperative Research Program for Agriculture Science \& Technology Development (Project No. PJ907047), Rural Development Administration, Republic of Korea.

\section{REFERENCES}

Aharoni, A., C. H. Ric de Vos, H. A. Verhoeven, C. A. Maliepaard, G. Kruppa, R. Bino, and D. B. Goodenowe. 2002. Nontargeted metabolome analysis by use of Fourier Transform Ion Cyclotron Mass Spectrometry. Omics. a journal of integrative biology. 6(3) : 217-234.

Baulcombe, D. C., S. Chapman, and S. Santa Cruz. 1995. Jellyfish green fluorescent protein as a reporter for virus infections. The Plant journal. for cell and molecular biology. 7(6) : 1045-1053.

Berthelot, K., D. Buret, B. Guerin, D. Delay, J. Negrel, and F. M. Delmotte. 1998. vir-Gene-inducing activities of hydroxycinnamic acid amides in Agrobacterium tumefaciens. Phytochemistry. 49(6) : 1537-1548.

Bhattacharya, A., P. Sood, and V. Citovsky. 2010. The roles of plant phenolics in defence and communication during Agrobacterium and Rhizobium infection. Molecular plant pathology. 11(5) : 705-719.

Brencic, A., A. Eberhard, and S. C. Winans. 2004. Signal quenching, detoxification and mineralization of vir geneinducing phenolics by the VirH2 protein of Agrobacterium tumefaciens. Molecular microbiology. 51(4) : 1103-1115.

Chalfie, M., Y. Tu, G. Euskirchen, W. W. Ward, and D. C. Prasher. 1994. Green fluorescent protein as a marker for gene expression. Science. 263(5148) : 802-805.

Clauser, K. R., P. Baker, and A. L. Burlingame. 1999. Role of accurate mass measurement (+/- $10 \mathrm{ppm})$ in protein identification strategies employing MS or MS/MS and database searching. Analytical chemistry. 71(14) : 2871-2882.

Cohen, M. F., Y. Sakihama, and H. Yamasaki. 2001. Roles of plant flavonoids in interactions with microbes. From protection against pathogens to the mediation of mutualism. Recent research developments in plant physiology : 157-173.
Cushnie, T. P. T., and A. J. Lamb. 2005. Antimicrobial activity of flavonoids. International journal of antimicrobial agents. 26(5) : 343-356.

Delzer, B. W., D. A. Somers, and J. H. Orf. 1990. Agrobacterium tumefaciens Susceptibility and Plant Regeneration of 10 Soybean Genotypes in Maturity Groups 00 to II. Crop Science. 30(2) : 320-322.

Ditt, R. F., E W Nester, and L. Comai. 2001. Plant gene expression response to Agrobacterium tumefaciens. Proceedings of the National Academy of Sciences of the United States of America. 98(19) : 10954-10959.

Donaldson, P. A. and D. H. Simmonds. 2000. Susceptibility to Agrobacterium tumefaciens and cotyledonary node transformation in short-season soybean. Plant Cell Reports. $19: 478-484$.

Ferrazzano, G. F., I. Amato, A. Ingenito, A. De Natale, and A. Pollio. 2009. Anti-cariogenic effects of polyphenols from plant stimulant beverages (cocoa, coffee, tea). Fitoterapia. 80(5) : 255-262.

Gage, D. J., T. Bobo, and S. R. Long. 1996. Use of green fluorescent protein to visualize the early events of symbiosis between Rhizobium meliloti and alfalfa (Medicago sativa). Journal of bacteriology. 178(24) : 7159-7166.

Gamborg, O. L., R. A. Miller, and K. Ojima. 1968. Nutrient requirements of suspension cultures of soybean root cells. Experimental Cell Research. 50(1) : 151-158.

Gelvin, S. B. 2000. Agrobacterium and plant genes involved in T-DNA transfer and integration. Annual review of plant physiology and plant molecular biology. $51: 223-256$.

Gunstone, F. 2001. Soybeans pace boost in oilseed production. Inform. $11:$ 1287-1289.

Hartmann, A., M. Schmid, D. van Tuinen, and G. Berg. 2009. Plant-driven selection of microbes. Plant and Soil. 321(1-2) : 235-257.

Hegde, V. R., P. Dai, M. Chu, M. Patel, R. Bryant, J. Terracciano, P. R. Das, and M. S. Puar. 1997. Neurokinin receptor inhibitors: fermentation, isolation, physico-chemical properties, structure and biological activity. The Journal of antibiotics. 50(12) : 983-991.

Hinchee, M. A. W., D. V. Connor-Ward, C. A. Newell, R. E. McDonnell, S. J. Sato, C. S. Gasser, D. A. Fischhoff, D. B. Re, R. T. Fraley, and R. B. Horsch. 1988. Production of Transgenic Soybean Plants Using Agrobacterium-Mediated DNA Transfer. Nature Biotechnology. 6(8) : 915-922

Hirai, M. Y., M. Yano, D. B. Goodenowe, S. Kanaya, T. Kimura, M. Awazuhara, M. Arita, T. Fujiwara, and Kazuki Saito. 2004. Integration of transcriptomics and metabolomics for understanding of global responses to nutritional stresses in Arabidopsis thaliana. Proceedings of the National Academy of Sciences of the United States of America. 101(27) : 10205-10210.

Holton, T. A. and E. C. Cornish. 1995. Genetics and Biochemistry 
of Anthocyanin Biosynthesis. The Plant cell. 7(7) : 1071-1083.

Horn, D. M., R. A. Zubarev, and F. W. McLafferty. 2000. Automated reduction and interpretation of high resolution electrospray mass spectra of large molecules. Journal of the American Society for Mass Spectrometry. 11(4) : 320-332.

Iijima, Y. et al. 2008. Metabolite annotations based on the integration of mass spectral information. The Plant journal. for cell and molecular biology. 54(5) : 949-962

Joubert, P., D. Beaupère, A. Wadouachi, S. Chateau, R. S. Sangwan, and B. S. Sangwan-Norreel. 2004a. Effect of phenolic glycosides on Agrobacterium tumefaciens virH gene induction and plant transformation. Journal of natural products. $67(3)$ : 348-351.

Joubert, P., D. Beaupère, A. Wadouachi, S. Chateau, R. S. Sangwan, and B. S. Sangwan-Norreel. 2004b. Effect of phenolic glycosides on Agrobacterium tumefaciens virH gene induction and plant transformation. Journal of natural products. $67(3): 348-351$.

Kado, C. I. and M. G. Heskett. 1970. Selective media for isolation of Agrobacterium, Corynebacterium, Erwinia, Pseudomonas, and Xanthomonas. Phytopathology. 60(6) : 969-976.

Ko, T.-S., S. Lee, S. K. Farrand, and S. S. Korban. 2004. A partially disarmed vir helper plasmid, pKYRT1, in conjunction with 2,4-dichlorophenoxyactic acid promotes emergence of regenerable transgenic somatic embryos from immature cotyledons of soybean. Planta. 218(4) : 536-541.

Koes, R. E., F. Quattrocchio, and J. N. M. Mol. 1994. The flavonoid biosynthetic pathway in plants. Function and evolution. BioEssays. 16(2) : 123-132.

Latha, S. and A. Mahadevan. 1997. Role of rhizobia in the degradation of aromatic substances. World Journal of Microbiology and Biotechnology. 13(6) : 601-607.

Long, S. R. 1996. Rhizobium symbiosis nod factors in perspective. The Plant cell. 8(10) : 1885-1898.

Matilla, M. A., M. Espinosa-Urgel, J. J. Rodríguez-Herva, J. L. Ramos, and M. I. Ramos-González. 2007. Genomic analysis reveals the major driving forces of bacterial life in the rhizosphere. Genome biology. 8(9) : R179.

Meurer, C. A., R. D. Dinkins, and G. B. Collins. 1998. Factors affecting soybean cotyledonary node transformation. Plant Cell Reports. 18(3-4) : 180-186.

Nakamura, Y. et al., 2007. Differential metabolomics unraveling light/dark regulation of metabolic activities in Arabidopsis cell culture. Planta. 227(1) : 57-66.

Negishi, O. and T. Ozawa. 2000. Inhibition of enzymatic browning and protection of sulfhydryl enzymes by thiol compounds. Phytochemistry. 54(5) : 481-487.

Nester, E. W. 1995. Plant Signaling in AgrobacteriumMediated Transformation Advances in Molecular Genetics of Plant-Microbe Interactions. Current Plant Science and Biotechnology in Agriculture 21 : 3-11.
Ohta, D., D. Shibata, and S. Kanaya. 2007. Metabolic profiling using Fourier-transform ion-cyclotron-resonance mass spectrometry. Analytical and bioanalytical chemistry. 389(5) : 1469-1475.

Oikawa, A., Y. Nakamura, T. Ogura, A. Kimura, H. Suzuki, N. Sakurai, Y. Shinbo, D. Shibata, S. Kanaya, and D. Ohta. 2006. Clarification of pathway-specific inhibition by Fourier transform ion cyclotron resonance/mass spectrometrybased metabolic phenotyping studies. Plant physiology. 142(2) : 398-413.

Olhoft, P. M., L. E. Flagel, C. M. Donovan, and David A Somers. 2003. Efficient soybean transformation using hygromycin B selection in the cotyledonary-node method. Planta. 216(5) : 723-735.

Olhoft P and D. Somers. 2001. L-Cysteine increases Agrobacteriummediated T-DNA delivery into soybean cotyledonary-node cells. Plant Cell Reports 20(8) : 706-711.

Oparka, K. J., A. G. Roberts, S. S. Cruz, P. Boevink, D. A. M. Prior, and A. Smallcombe. 1997. Using GFP to study virus invasion and spread in plant tissues. Nature. 388 : 401-402.

Owens, L. D. and A. C. Smigocki. 1988. Transformation of Soybean Cells Using Mixed Strains of Agrobacterium tumefaciens and Phenolic Compounds. Plant physiology. 88(3) : 570-573.

Parker, J. E., M. J. Coleman, V. Szabò, L. N. Frost, R. Schmidt, E. A. van der Biezen, T. Moores, C. Dean, M. J. Daniels, and J. D. Jones. 1997. The Arabidopsis downy mildew resistance gene RPP5 shares similarity to the toll and interleukin-1 receptors with $\mathrm{N}$ and L6. The Plant cell. 9(6) : 879-894.

Santarém, E. R., H. N. Trick, J. S. Essig, and J. J. Finer. 1998. Sonication-assisted Agrobacterium-mediated transformation of soybean immature cotyledons optimization of transient expression. Plant Cell Reports. 17(10) : 752-759.

Schmutz, J. et al. 2010. Genome sequence of the palaeopolyploid soybean. Nature. 463(7278) : 178-183.

Shinbo, Y., Y. Nakamura, M. Altaf-Ul-Amin, H. Asahi, K. Kurokawa, M. Arita, K. Saito, D. Ohta, D. Shibata, and S. Kanaya. 2006. KNApSAcK: A Comprehensive SpeciesMetabolite Relationship Database. Plant Metabolomics. 57 : $165-181$.

Spencer, P. A. and G. H. N. Towers. 1988. Specificity of signal compounds detected by Agrobacterium tumefaciens. Phytochemistry. 27(9) : 2781-2785.

Stachel, S. E., E. Messens, M. V. Montagu, and P. Zambryski. 1985. Identification of the signal molecules produced by wounded plant cells that activate T-DNA transfer in Agrobacterium tumefaciens. Nature. 318(6047) : 624-629.

Stougaard, J. 2000. Regulators and regulation of legume root nodule development. Plant physiology. 124(2) : 531-540. 
Strohalm, M., D. Kavan, P. Novák, M. Volný, and V. Havlícek. 2010. mMass 3: a cross-platform software environment for precise analysis of mass spectrometric data. Analytical chemistry. 82(11) : 4648-4651.

Taguri, T., T. Tanaka, and I. Kouno. 2006. Antibacterial spectrum of plant polyphenols and extracts depending upon hydroxyphenyl structure. Biological \& pharmaceutical bulletin. 29(11) : 2226-2235.

Tang, W. 2003. Additional virulence genes and sonication enhance Agrobacterium tumefaciens-mediated loblolly pine transformation. Plant cell reports. 21(6) : 555-562.

Tautenhahn, R., C. Böttcher, and S. Neumann. 2007. Annotation of LC/ESI-MS Mass Signals. Bioinformatics Research and Development. 4414 : 371-380.

Titulaer, M. K., I. Siccama, L. J. Dekker, A. L. C. T. van Rijswijk, R. M. A. Heeren, P. A. Sillevis Smitt, and T. M. Luider. 2006. A database application for pre-processing, storage and comparison of mass spectra derived from patients and controls. BMC bioinformatics. $7: 403$.

Trick, H. N. and J. J. Finer. 1998. Sonication-assisted Agrobacterium-mediated transformation of soybean [Glycine $\max ($ L.) Merrill] embryogenic suspension culture tissue. Plant Cell Reports. 17(6-7) : 482-488.

Trick, H. N. and J. J. Finer. 1997. SAAT: sonication-assisted Agrobacterium-mediated transformation. Transgenic Research. 6(5) : 329-336.
Tzfira, T. and V. Citovsky. 2002. Partners-in-infection: host proteins involved in the transformation of plant cells by Agrobacterium. Trends in cell biology. 12(3) : 121-129.

Veena, H. Jiang, R. W. Doerge, and S. B. Gelvin. 2003. Transfer of T-DNA and Vir proteins to plant cells by Agrobacterium tumefaciens induces expression of host genes involved in mediating transformation and suppresses host defense gene expression. The Plant journal. 35(2) : 219-236.

Yan, B., M. S. S. Reddy, G. B. Collins, and R. D. Dinkins. 2000. Agrobacterium tumefaciens- mediated transformation of soybean [Glycine max (L.) Merrill.] using immature zygotic cotyledon explants. Plant Cell Reports. 19(11) : 1090-1097.

Zaltsman, A., A. Krichevsky, S. V. Kozlovsky, F. Yasmin, and V. Citovsky. 2010. Plant defense pathways subverted by Agrobacterium for genetic transformation. Plant signaling \& behavior. 5(10) : 1245-1248.

Zeng, P., D. A. Vadnais, Z. Zhang, and J. C. Polacco. 2004. Refined glufosinate selection in Agrobacterium-mediated transformation of soybean [Glycine max (L.) Merrill]. Plant cell reports. 22(7) : 478-482.

Zerback, R., K. Dressler, and D. Hess. 1989. Flavonoid compounds from pollen and stigma of Petunia hybrid, Inducers of the vir region of the Agrobacterium tumefaciens Ti plasmid. Plant Science. 62(1) : 83-91. 